\title{
O PROGRAMA DE AQUISIÇÃO DE ALIMENTOS - PAA: A EVOLUÇÃO DE UMA POLÍTICA PÚBLICA MÚLTIPLA
}

Carla Hentz ${ }^{1}$

Rosangela Aparecida de Medeiros Hespanhol ${ }^{2}$

Resumo: Este trabalho tem como objetivo apresentar e analisar variáveis que caracterizam a evolução do Programa de Aquisição de Alimentos (PAA), no período entre 2003 e 2015. Institucionalizado no ano de 2003 como uma ação estruturante do Programa Fome Zero, as ações do programa promovem a articulação entre a produção, a comercialização e o consumo, conjugando elementos da política agrícola e da política de segurança alimentar, visando colaborar com o enfrentamento da fome e da pobreza e, ao mesmo tempo, promover a inclusão produtiva no campo. Desta forma, efetuar-se-á uma análise da trajetória do PAA em escala nacional, como também por macrorregiões (Centro-Oeste, Nordeste, Norte, Sudeste e Sul). É possível afirmar que, embora o programa surja como resposta e possibilidade de transformação social no meio rural, sua abrangência em termos de estabelecimentos da agricultura familiar ainda é limitada.

Palavras-chave: Política pública. Programa de Aquisição de Alimentos. Agricultura familiar.

\section{THE FOOD ACQUISITION PROGRAM - PAA: THE EVOLUTION OF A MULTIPLE PUBLIC POLICY}

Abstract: This paper aims to present topics that characterize the evolution of the Food Acquisition Program (PAA) in the period from 2003 to 2015. Institutionalized in 2003 as a structuring action of the Zero Hunger Program, the actions of the program allied elements of agricultural policy and food security policy, enabling the articulation between production, marketing and consumption, aiming at collaborating with the fight against hunger and poverty in Brazil and, at the same time, strengthening family farming. To do this, an analysis of the PAA trajectory will be carried out on a national scale, as well as macro-regions (Center-West, Northeast, North, Southeast and South). It is possible to affirm, given the results obtained with the research that, although the resources destined to the program have been significantly expanded, their scope is still limited and concentrated in spatial terms.

Keywords: Public policy. Food Acquisition Program. Family farming.

\section{EL PROGRAMA DE ADQUISICIÓN DE ALIMENTOS - PAA: LA EVOLUCIÓN DE UNA POLÍTICA PÚBLICA MÚLTIPLE}

Resumen: Este trabajo tiene como objetivo presentar y analizar variables que caracterizan la evolución del Programa de Adquisición de Alimentos (PAA), en el período entre 2003 y 2015. Institucionalizado en el año 2003 como una acción estructurante del Programa Hambre Cero, las acciones del programa promueven la articulación entre la producción, la comercialización y el consumo, combinando

\footnotetext{
${ }^{1}$ Universidade Estadual Paulista - UNESP, Departamento de Geografia, Presidente Prudente, Brasil, carla.hentz@gmail.com, https://orcid.org/0000-0002-3849-8831

2 Universidade Estadual Paulista - UNESP, Departamento de Geografia, Presidente Prudente, Brasil, medeiroshespanhol@gmail.com, https://orcid.org/ 0000-0002-5073-8308
} 
elementos de la política agrícola y de la política de seguridad alimentaria, con el fin de colaborar con el enfrentamiento del hambre y la pobreza y al mismo tiempo promover la inclusión productiva en el campo. De esta forma, se efectuará un análisis de la trayectoria del PAA a escala nacional, así como por macrorregiones (Centro-Oeste, Nordeste, Norte, Sudeste y Sur). Es posible afirmar que, aunque el programa surja como respuesta y posibilidad de transformación social en el medio rural, su alcance en términos de establecimientos de la agricultura familiar todavía es limitado.

Palabras clave: Política pública. Programa de Adquisición de Alimentos. Agricultura familiar.

\section{Introdução}

Nas últimas décadas do século $X X$, discursos em defesa da agricultura familiar e o estabelecimento de algumas políticas públicas direcionadas a essa categoria de produtores rurais ganharam destaque, todos infundidos de argumentos que buscavam mostrar a importância desta categoria social, tanto para a sociedade - por ser a produtora e fornecedora de alimentos -, como também para a economia do país e, principalmente, pela importância social que esta detém como grande absorvedora de mão-de-obra rural (SCHNEIDER, 2003).

Anteriormente à década de 1990, os debates sobre as políticas públicas para a agricultura familiar não eram tarefa fácil, haja vista que a agricultura familiar "durante muito tempo, foi considerada inferior e arcaica, cuja produção, não seria capaz de gerar riqueza ou, até mesmo, contribuir para o crescimento e desenvolvimento do Brasil" (VALNIER; RICCI, 2013, p. 200). Foi somente em meados da década de 1990, que o Estado brasileiro reconheceu a importância da agricultura familiar para o desenvolvimento do país, criando políticas que servissem de base para a reprodução social desse segmento. Estas mudanças ocorrem de forma lenta e gradual e caracterizam-se por ações direcionadas à liberação de crédito à produção (de custeio e investimento), garantia de preços e, de forma incipiente, algumas atuações específicas para a assistência técnica.

As políticas públicas no contexto posterior a década de 1990 passam a ser engendradas valorizando, sobretudo, os aspectos econômicos, sociais e políticos existentes em seus territórios. Para Hespanhol (2010, p. 124), "o Estado brasileiro introduziu, pelo menos no nível de concepção e de operacionalização, novos aportes à parte das políticas públicas direcionadas ao campo brasileiro". A ênfase às políticas públicas passa a ser intensificada com a criação da Secretaria de Desenvolvimento Territorial (SDT), que tem intensificado a necessidade do enfoque 
territorial, a partir do entendimento que o espaço rural adquiriu um caráter cada vez mais multidimensional (pluriativo) e menos setorial (essencialmente agrícola) (OLIVEIRA, 2010).

Essa problemática ganha maior relevância a partir de 2003, com a eleição do presidente Luís Inácio Lula da Silva e a criação do Fome Zero. Criado no âmbito do Programa Fome Zero, o Programa de Aquisição de Alimentos (PAA), tem por objetivos atenuar a fome e a pobreza no Brasil e, ao mesmo tempo, fortalecer a agricultura familiar.

Nesta perspectiva, optamos por realizar uma análise do PAA, tanto em nível nacional, como também, por macrorregiões. Destarte, para apresentar as análises efetuadas nesta pesquisa realizou-se revisão bibliográfica acerca dos temas, bem como, levantamento de dados de fonte secundária em sites oficiais do IBGE (Censo Agropecuário de 2006), Ministério do Desenvolvimento Social e Combate à Fome (MDS), Ministério do Desenvolvimento Agrário (MDA), Companhia Nacional de Abastecimento (CONAB), entre outros.

O presente artigo está estruturado, além desta introdução, das considerações finais e das referências, em um item, contendo cinco subtópicos, quais sejam: Municípios atendidos pelo PAA; Evolução orçamentária; Quantidade de produtos (t); Número de agricultores beneficiados; e Evolução do número de projetos aprovados.

\section{Agricultura familiar e políticas públicas: a evolução do Programa de Aquisição de Alimentos}

Instituído em julho de 2003, por meio do artigo 19 da lei no 10.696, o PAA reúne ações que apoiam o acesso aos alimentos às populações em situação de insegurança alimentar e nutricional, garantindo quantidade, qualidade e regularidade necessárias, bem como promover a inclusão social no campo por meio do fortalecimento da agricultura familiar (BRASIL. CONAB, 2015). Lançado pelo Ministério do Desenvolvimento Social e Combate à Fome como uma das políticas estruturais do Programa Fome Zero, a criação do PAA representa um marco na política agrícola brasileira, pois revela a presença do Estado junto à agricultura familiar.

Inserido em um amplo debate sobre desenvolvimento e distribuição de renda, as ações do programa envolvem a União, os Estados e os municípios, parceria esta que permitiu a aproximação do poder local com a produção familiar rural. 
Viabilizando a articulação entre a produção, a comercialização e o consumo, as ações do programa favorecem a inserção da agricultura familiar nos mercados institucionais. Um dos aspectos inovadores do programa e que o elencam como uma das mais importantes políticas públicas de comercialização governamental é, justamente, o esforço para integrar, não apenas em sua concepção, mas também nos aspectos práticos de sua operacionalização, dimensões relacionadas tanto à política agrícola quanto à política de segurança alimentar e nutricional (SCHMITT, 2005).

O programa além de valorizar a cultura alimentar das populações e garantir a formação de estoques estratégicos através da produção, incentiva também, o manejo agroecológico e a preservação da biodiversidade. Todavia, tem sua principal importância atribuída ao fato de considerar a magnitude da agricultura familiar para o meio rural brasileiro e, sobretudo, os desafios e problemas enfrentados por esse segmento referente à comercialização.

Segundo Campos e Bianchini (2014, p. 17), o PAA inovou "quando definiu como seus objetivos centrais fortalecer a agricultura familiar, de um lado, e promover a segurança alimentar e o combate à fome, de outro [...]". Com o mesmo recurso financeiro fortaleceu a agricultura familiar por meio da aquisição de alimentos e promoveu o acesso a alimentação. Para Delgado (2013, p. 5), o PAA cumpriu um virtuoso papel no desenvolvimento rural, qual seja, "o de induzir a elevação do excedente econômico dos produtores familiares de alimentos, mediante ação estrita de garantia de comercialização e de fortalecimento de suas organizações associativas".

Como sugere Mielitz (2014, p. 61), o surgimento do PAA "deve ser compreendido como parte de um conjunto de instrumentos constitutivos de uma reorientação nos papéis esperados e/ou funções atribuídas ao mundo rural e à produção agrícola [...]", particularmente no que diz respeito à agricultura familiar. A construção do programa ocorreu em um contexto de transformações, em que o Estado brasileiro passa a redirecionar suas prioridades, principalmente no tocante aos recursos públicos, no reconhecimento da agricultura familiar e na importância da segurança alimentar e nutricional

Em termos institucionais, a operacionalização do PAA está associada ao Pronaf, sendo condição sine qua non possuir a Declaração de Aptidão ao Pronaf (DAP). O público alvo é constituído por agricultores familiares, assentados da reforma agrária, silvicultores, aquicultores, pescadores artesanais, indígenas e 
integrantes de comunidades de quilombolas rurais e demais povos e comunidades (BRASIL. CONAB, 2015). O programa é de natureza interministerial, sendo formado por um Grupo Gestor integrado pelo Ministério da Agricultura, Pecuária e Abastecimento (MAPA), Ministério do Desenvolvimento Agrário (MDA), Ministério do Desenvolvimento Social e Combate à Fome (MDS), Ministério da Fazenda (MF) e Ministério do Planejamento, Orçamento e Gestão (MPOG).

É por meio do Grupo Gestor que são definidas as normas, o assessoramento e o acompanhamento das atividades, tais como: definição dos preços a serem pagos, a seleção das regiões beneficiarias, os modos de aquisição dos produtos, as doações e vendas dos produtos adquiridos, a formação de estoques públicos, dentre outras ações. A execução do programa fica a cargo dos governos estaduais, municipais e da Companhia Nacional de Abastecimento (CONAB), por meio de diferentes modalidades que seguem limites de valores máximos por agricultor/ano. As aquisições são efetuadas com a dispensa de licitação, cabendo aos Conselhos Municipais de Segurança Alimentar e Nutricional (CONSEAS), o dever de fiscalizar a execução do programa. Além dos vários atores envolvidos na execução, o programa, ao longo de sua trajetória, foi sendo aprimorado em seu arcabouço jurídico e institucional, sendo constituído por seis modalidades diferentes como podemos visualizar no (Quadro 1).

\begin{tabular}{|c|c|c|c|c|}
\hline $\begin{array}{l}\text { MODALIDADES/ } \\
\text { FONTE DOS } \\
\text { RECURSOS }\end{array}$ & $\begin{array}{l}\text { ORGÃO } \\
\text { EXECUTOR }\end{array}$ & $\begin{array}{l}\text { FORMA DE } \\
\text { ACESSO }\end{array}$ & OBJETIVOS & $\begin{array}{l}\text { LIMITES POR } \\
\text { DAP }\end{array}$ \\
\hline $\begin{array}{l}\text { Compra Direta } \\
\text { da Agricultura } \\
\text { Familiar - } \\
\text { CDAF } \\
\text { (MDS/MDA) }\end{array}$ & CONAB & $\begin{array}{l}\text { Individual, } \\
\text { Cooperativa } \\
e \\
\text { Associação }\end{array}$ & $\begin{array}{l}\text { Tem por objetivo a melhoria na } \\
\text { comercialização da produção familiar } \\
\text { por duas formas: formação de } \\
\text { estoques e a agregação de valor ao } \\
\text { produto por meio do processamento. }\end{array}$ & $\begin{array}{c}\mathbf{R} \$ \\
8.000,00\end{array}$ \\
\hline $\begin{array}{l}\text { Compra com } \\
\text { Doação } \\
\text { Simultânea - } \\
\text { CDS } \\
\text { (MDS) }\end{array}$ & $\begin{array}{l}\text { CONAB, } \\
\text { Estados e } \\
\text { Municípios }\end{array}$ & $\begin{array}{l}\text { Individual, } \\
\text { Cooperativa } \\
\text { e } \\
\text { Associação }\end{array}$ & $\begin{array}{l}\text { Destina-se à aquisição de alimentos } \\
\text { da agricultura familiar com vistas à } \\
\text { doação a populações em situação de } \\
\text { risco alimentar atendidas por } \\
\text { entidades sociais de caráter } \\
\text { governamental e não-governamental. } \\
\text { Via Conab }(\mathrm{R} \$ 8.000,00) \text { e via Termo } \\
\text { de Adesão }(\mathrm{R} \$ 6.500,00)\end{array}$ & $\begin{array}{l}\mathbf{R} \$ \\
8.000,00 \\
\text { ou } \\
\mathbf{R} \$ \\
6.500,00\end{array}$ \\
\hline $\begin{array}{c}\text { Formação de } \\
\text { Estoque pela } \\
\text { Agricultura } \\
\text { Familiar - CPR } \\
\text { Estoque } \\
\text { (MDS/MDA) }\end{array}$ & CONAB & $\begin{array}{l}\text { Cooperativa } \\
\text { e Associação }\end{array}$ & $\begin{array}{l}\text { Tem por objetivo adquirir alimentos da } \\
\text { safra vigente para a formação de } \\
\text { estoques em suas próprias } \\
\text { organizações. A organização adquire } \\
\text { a produção dos agricultores familiares } \\
\text { listados na Proposta de Participação, } \\
\text { beneficia os alimentos e os mantém } \\
\text { em estoque próprio até sua entrega } \\
\text { para estoques públicos ou }\end{array}$ & $\begin{array}{c}R \$ \\
8.000,00\end{array}$ \\
\hline
\end{tabular}




\begin{tabular}{|c|c|c|c|c|}
\hline & & & $\begin{array}{l}\text { comercialização no mercado } \\
\text { convencional. }\end{array}$ & \\
\hline $\begin{array}{l}\text { Incentivo à } \\
\text { Produção e ao } \\
\text { Consumo de } \\
\text { Leite - IPCL } \\
\text { (MDS) }\end{array}$ & $\begin{array}{l}\text { Estados do } \\
\text { Nordeste e } \\
\text { norte de } \\
\text { Minas } \\
\text { Gerais }\end{array}$ & $\begin{array}{c}\text { Individual, } \\
\text { Cooperativa } \\
e \\
\text { Associação }\end{array}$ & $\begin{array}{l}\text { A IPCL busca assegurar o consumo } \\
\text { de leite a gestantes, crianças, } \\
\text { nutrizes, idosos e outros públicos } \\
\text { prioritários. Restringe-se a área de } \\
\text { atuação da Sudene*, beneficiando os } \\
\text { estados do Nordeste e Norte de } \\
\text { Minas Gerais. A aquisição é feita de } \\
\text { agricultores com produção máxima de } \\
150 \text { litros dia e compra limitada em } \\
100 \text { litros por dia. O leite é } \\
\text { pasteurizado em laticínios contratados } \\
\text { e distribuído para famílias em postos } \\
\text { instalados nos locais de concentração } \\
\text { dos beneficiários. }\end{array}$ & $\begin{array}{c}R \$ \\
4.000,00 \\
\text { por } \\
\text { semestre. }\end{array}$ \\
\hline $\begin{array}{c}\text { Compra } \\
\text { Institucional } \\
-\end{array}$ & $\begin{array}{l}\text { Recursos } \\
\text { do } \\
\text { proponente }\end{array}$ & $\begin{array}{c}\text { Individual, } \\
\text { Cooperativa } \\
\text { e } \\
\text { Associação }\end{array}$ & $\begin{array}{c}\text { A modalidade tem por objetivo realizar } \\
\text { compras voltadas para o atendimento } \\
\text { de demandas regulares de consumo } \\
\text { (restaurantes universitários, presídios, } \\
\text { hospitais, academias de polícia, entre } \\
\text { outros) por parte da União, Estados, } \\
\text { Distrito Federal e municípios. }\end{array}$ & $\begin{array}{c}R \$ \\
20.000,00\end{array}$ \\
\hline $\begin{array}{l}\text { Aquisição de } \\
\text { Sementes } \\
\text { (MDS) }\end{array}$ & CONAB & $\begin{array}{l}\text { Cooperativa } \\
\text { e Associação }\end{array}$ & $\begin{array}{l}\text { A modalidade permite a compra de } \\
\text { sementes pela Conab para atender às } \\
\text { demandas de organizações } \\
\text { previamente definidas e sua } \\
\text { distribuição aos beneficiários } \\
\text { consumidores. }\end{array}$ & $\begin{array}{c}R \$ \\
6.000,00\end{array}$ \\
\hline
\end{tabular}

A execução é praticada em âmbito nacional e de forma descentralizada, por meio de parcerias com governos estaduais e municipais, integrados as políticas de desenvolvimento agrícola e social. Embora não esteja isento de críticas e desafios, os resultados do programa são satisfatórios, sobretudo na redução da pobreza e na segurança alimentar e nutricional, isto porque o programa serve de amparo a duas etapas fundamentais do suprimento alimentar: o momento produtivo e o de acesso aos produtos.

\section{Municípios atendidos pelo PAA}

Desde que foi implantado, o programa vem beneficiando inúmeros municípios e produtores familiares por meio da geração de renda, aumento da produção agrícola e, em especial, melhoria na qualidade da alimentação de pessoas que vivem em situação de insegurança alimentar e nutricional. Ao longo dos anos, o PAA apresentou um expressivo crescimento, ampliando sua capilaridade nacional, 
estando presente de 2003 a 2015, em 2.729 (49\%) municípios do total de 5.570 municípios brasileiros. Na tabela 1 podemos verificar a evolução do número de municípios atendidos, de pessoas e de unidades recebedoras no período entre 2003 e 2015.

\begin{tabular}{lccc}
\hline Ano & $\begin{array}{c}\text { № de municípios } \\
\text { atendidos }\end{array}$ & $\begin{array}{c}\text { № de atendimentos em } \\
\text { termos de pessoas }\end{array}$ & $\begin{array}{c}\text { № unidades } \\
\text { recebedoras }\end{array}$ \\
\hline 2003 & 104 & 145.987 & 0 \\
\hline 2004 & 293 & 540.027 & 0 \\
\hline 2005 & 528 & 2.079 .937 & 0 \\
\hline 2006 & 950 & 4.290 .986 & 0 \\
\hline 2007 & 976 & 7.580 .948 & 0 \\
\hline 2008 & 976 & 10.643 .207 & 0 \\
\hline 2009 & 963 & 8.129 .258 & 11.572 \\
\hline 2010 & 1.076 & 14.292 .020 & 17.744 \\
\hline 2011 & 1.177 & 16.290 .738 & 17.222 \\
\hline 2012 & 1.180 & 18.208 .960 & 17.988 \\
\hline 2013 & 524 & 7.981 .161 & 4.449 \\
\hline 2014 & 619 & 11.460 .634 & 3.968 \\
\hline 2015 & 541 & 10.960 .664 & 2.829 \\
\hline
\end{tabular}

Tabela 1: Número de municípios atendidos, número de atendimentos em relação às pessoas e unidades recebedoras. PAA-Brasil - 2003-2015

Fonte: BRASIL. CONAB: Ações da Conab - PAA 2003 a 2015. Org. dos autores.

As informações da tabela 1 mostram que o maior número de municípios beneficiados ocorreu no ano de 2012, sendo atendidos 1.180 municípios. Paralelamente ao crescimento do número de municípios até o ano de 2012, o atendimento de pessoas em insegurança alimentar e nutricional passou de 145.987 em 2003, para 18.208.960 em 2012. Neste mesmo ano, 17.988 unidades recebedoras foram beneficiadas. No ano seguinte (2013), as reduções foram expressivas em todas as variáveis consideradas na tabela 1, sendo de $55 \%$ no número de municípios, $56 \%$ no número de atendimentos e $75 \%$ no número de unidades recebedoras. A partir de 2013, as variáveis apresentam oscilações positivas e negativas de crescimento. Para o ano de 2015, 541 municípios foram atendidos, o que corresponde a $9,67 \%$ do total.

A despeito da ampliação do programa, Hespanhol (2013, p. 1) destaca que a abrangência do programa em nível nacional ainda é limitada se considerarmos o total de estabelecimentos da agricultura familiar e "pela importância que esta política possui em relação à agricultura familiar e à segurança alimentar no país". As reduções ocorridas a partir do ano de 2013 podem estar associadas às adequações e atualizações feitas no Manual de Operações da Conab (MOC) e do Normativo de 
Operações da Conab (NOC), os quais passaram a vigorar com novas normas, limitando o acesso por parte dos municípios e fornecedores beneficiados; aos inúmeros casos de mau uso dos recursos do programa em nível de Brasil (desvios e fraudes) por parte das entidades proponentes, resultando na suspenção e/ou cancelamento do programa nestas localidades; aos problemas climáticos (secas e enchentes) nas diferentes regiões brasileiras; a obrigatoriedade por parte dos municípios de dispor de um Banco de Alimentos para acessar o programa, como também da participação de pelo menos 40\% de mulheres no PAA a partir de 2011 atualizações estas que passam a impor novas exigências de acesso -; e, para o ano de 2015, esta redução também pode estar associada ao momento de estagnação econômica que o país enfrentou.

Este conjunto de fatores explica, em parte, as oscilações (positivas e negativas) que ocorreram no programa no decorrer dos anos, sendo aplicável ao montante de recursos, ao número de municípios participantes, a quantidade de produtos adquirida, ao número de agricultores fornecedores e ao número de projetos aprovados em nível de Brasil e das regiões.

\section{Evolução orçamentária do PAA}

No período compreendido entre o ano de 2003 até dezembro de 2015, o Governo Federal já investiu mais de três bilhões de reais na execução do PAA, sendo apresentado na figura 1 a distribuição dos recursos por ano.

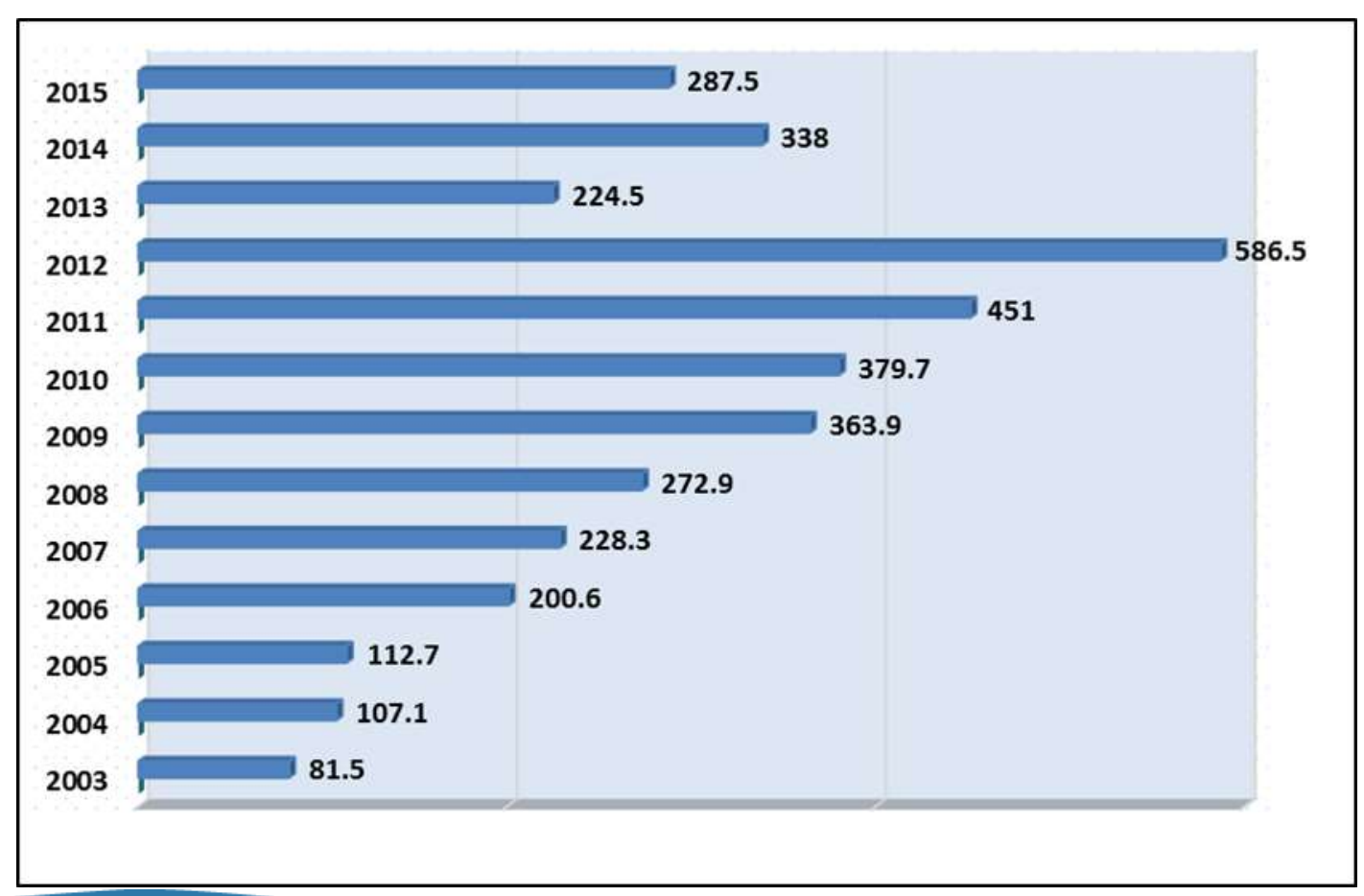


Figura 1: Distribuição orçamentária (em milhões de reais). PAA-Brasil - 2003-2015

Fonte: BRASIL. CONAB: Ações da Conab - PAA 2003 a 2015. Org. dos autores.

Os recursos destinados pelo MDS e MDA ao PAA foram sendo incrementados no decorrer dos anos, o qual apresentou uma trajetória ascendente de 2003 a 2012. Nos anos seguintes, 2013, 2014 e 2015 houve uma significativa redução nos valores destinados ao programa. De acordo com o Relatório Anual da Conab de 2015, a redução é devida "às características de cada região, em termos de organização social local e o acesso à informação por parte dos beneficiários fornecedores ou de suas representações legais" (BRASIL, 2016, p. 6). Observa-se, na tabela 2, o desempenho do PAA por regiões, o qual se apresentou variável no decorrer dos anos.

\begin{tabular}{|c|c|c|c|c|c|c|}
\hline \multirow[t]{2}{*}{ ANO } & \multicolumn{5}{|c|}{ REGIÕES } & \multirow{2}{*}{$\begin{array}{l}\text { TOTAL } \\
\text { (Reais) }\end{array}$} \\
\hline & C. OESTE & NORDESTE & NORTE & SUDESTE & SUL & \\
\hline 2003 & 12.238 .974 & 31.672 .408 & 12.386 .912 & 7.603 .665 & 17.639 .249 & 81.541 .207 \\
\hline 2004 & 3.386 .094 & 42.307 .978 & 28.391 .528 & 8.903 .396 & 24.196 .831 & 107.185 .826 \\
\hline 2005 & 5.538 .352 & 34.745 .917 & 16.149 .222 & 13.876 .678 & 42.481 .492 & 112.791 .660 \\
\hline 2006 & 10.045 .899 & 54.857 .717 & 17.812 .507 & 32.440 .707 & 85.510 .564 & 200.667.394 \\
\hline 2007 & 8.706 .953 & 56.116 .343 & 18.799 .859 & 42.080 .968 & 102.648 .840 & 228.352.964 \\
\hline 2008 & 9.893 .516 & 80.838 .353 & 15.679 .112 & 73.486 .284 & 93.032 .175 & 272.929.439 \\
\hline 2009 & 13.225 .303 & 102.830 .480 & 15.549 .939 & 78.842 .348 & 153.516 .158 & 363.964 .228 \\
\hline 2010 & 21.400 .943 & 121.858 .906 & 28.348 .787 & 79.151 .714 & 128.975 .115 & 379.735 .466 \\
\hline 2011 & 32.025 .103 & 153.674 .198 & 29.386 .137 & 111.741 .509 & 124.209 .257 & 451.036 .204 \\
\hline 2012 & 43.282 .942 & 154.904 .344 & 36.045 .217 & 131.776 .716 & 220.557 .912 & 586.567 .131 \\
\hline 2013 & 24.075 .247 & 66.487 .273 & 22.938 .796 & 67.812 .376 & 43.203 .433 & 224.517.124 \\
\hline 2014 & 31.155 .531 & 79.992 .989 & 37.860 .917 & 128.709 .065 & 60.286 .440 & 338.004 .942 \\
\hline 2015 & 29.589 .161 & 92.549 .198 & 33.399 .258 & 77.902 .561 & 54.075 .037 & 287.515.216 \\
\hline Total & 244.564 .018 & 1.072 .836 .104 & 312.748 .191 & 854.327 .987 & 1.150 .332 .503 & 3.634 .808 .801 \\
\hline
\end{tabular}

Tabela 2: Recursos aplicados. PAA-Regiões - 2003-2015

Fonte: BRASIL. CONAB: Ações da Conab - PAA 2003 a 2015. Org. dos autores.

Destaque para o ano de 2012 que apresentou um expressivo incremento nos recursos investidos, totalizando 586,5 milhões de reais, sendo a região Sul que abarcou a maior parcela (i.e., 220,5 milhões de reais). As regiões que apresentaram os maiores índices de crescimento no ano de 2012 em comparação ao ano de 2011 foram as regiões Sul $(77 \%)$, Centro-Oeste (35\%) e Norte (22\%). Tomando esta análise para o conjunto dos dados, é possível perceber que as regiões Sul e 
Nordeste abarcaram de 2003 a 2015, 2/3 do total de recursos investidos, ao passo que Centro-Oeste, Norte e Sudeste equivalem, juntas, a apenas 1/3 do total.

Em contrapartida, no ano de 2013, o decréscimo foi de $61 \%$ no valor dos recursos investidos no PAA em nível nacional, sendo aplicados somente $38 \%$ do valor dos recursos, em comparação com o ano de 2012. Os valores investidos voltam a apresentar crescimento positivo em 2014, seguido de um novo decréscimo em 2015 (i.e., 338 milhões para 287,5 milhões, respectivamente).

A região Sul deteve de 2003 a 2015, a maior parcela na alocação dos recursos do PAA, tendo em vista que possui um elevado grau de organização coletiva (associações/cooperativas) e de produção de pequenos agricultores, o que de fato facilita o acesso ao programa. Do total de 3,6 bilhões de reais investidos pelo PAA no Brasil, 1,1 bilhões de reais (31,64\%) foram aplicados nos três estados da região Sul. A segunda maior parcela foi investida na região Nordeste, sendo de 1,07 bilhões de reais $(29,51 \%)$.

Isto pode ser explicado, em parte, pela elevada concentração de estabelecimentos da agricultura familiar nas regiões Nordeste e Sul, $48 \%$ e $22 \%$, respectivamente (Figura 2 ).

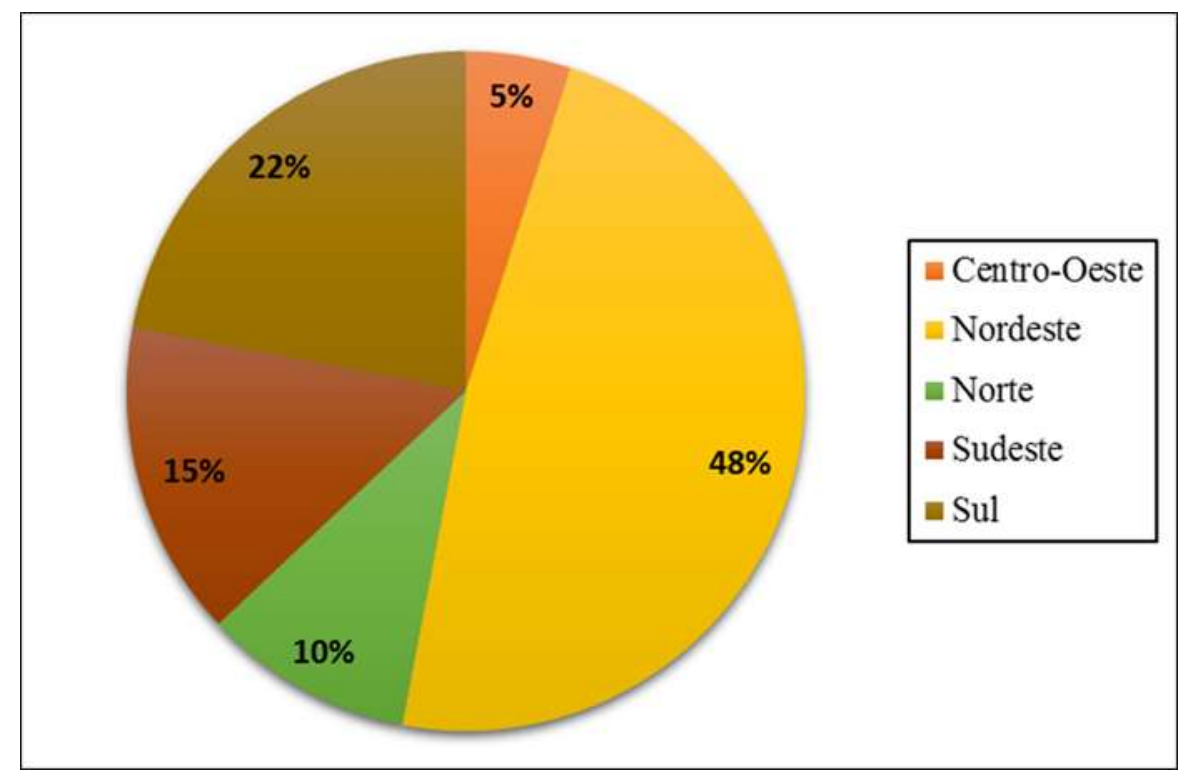

Figura 2: Distribuição geográfica do número de agricultores familiares no Brasil (\%). Fonte: IBGE - (Censo Agropecuário de 2006). Org. dos autores.

Em contrapartida, as regiões Centro-Oeste e Norte apresentam menor participação no PAA em relação às outras regiões, e também correspondem às regiões com menos número de estabelecimentos familiares, $5 \%$ e $10 \%$, 
respectivamente, de acordo com os dados do IBGE - (Censo Agropecuário de 2006).

Para a região Sul, este fator pode também estar associado ao maior estágio de desenvolvimento das cadeias produtivas nas quais se inserem os agricultores familiares, ao elevado grau de organização coletiva (associações e cooperativas), conforme já mencionado anteriormente, e ao maior acesso a serviços de assistência técnica e extensão rural para elaboração dos projetos.

Quantidade de produtos (t)

Conforme já destacado, diversos foram os fatores que influenciaram na baixa execução do PAA no ano de 2013, sendo o fator produção o que mais interfere no desenvolvimento das atividades. Em se tratando de produção, até o ano de 2015 já foram adquiridas 2.574.101 toneladas de alimentos, como pode ser verificado na tabela 3.

\begin{tabular}{rrrrrrr}
\hline \multirow{2}{*}{ ANO } & \multicolumn{3}{c}{ QUANTIDADE DE PRODUTOS POR REGIÃO } & TOTAL \\
\cline { 2 - 5 } & C. OESTE & NORDESTE & NORTE & SUDESTE & \multicolumn{1}{c}{ SUL } & \multicolumn{1}{c}{$(\mathbf{t})$} \\
\hline 2003 & 31.382 & 41.133 & 17.749 & 12.673 & 32.307 & $\mathbf{1 3 5 . 2 4 4}$ \\
\hline 2004 & 4.355 & 78.656 & 37.168 & 26.540 & 10.709 & $\mathbf{1 5 7 . 4 2 8}$ \\
\hline 2005 & 10.924 & 102.582 & 19.446 & 10.855 & 12.634 & $\mathbf{1 5 6 . 4 4 0}$ \\
\hline 2006 & 16.312 & 54.099 & 18.845 & 29.050 & 93.888 & $\mathbf{2 1 2 . 1 9 3}$ \\
\hline 2007 & 9.570 & 37.945 & 19.305 & 30.533 & 106.232 & $\mathbf{2 0 3 . 5 8 5}$ \\
\hline 2008 & 5.611 & 44.065 & 13.323 & 48.694 & 63.023 & $\mathbf{1 7 4 . 7 1 7}$ \\
\hline 2009 & 11.401 & 67.171 & 11.815 & 58.216 & 139.413 & $\mathbf{2 8 8 . 0 1 6}$ \\
\hline 2010 & 18.996 & 67.134 & 17.962 & 53.514 & 68.289 & $\mathbf{2 2 5 . 8 9 5}$ \\
\hline 2011 & 16.378 & 85.358 & 18.237 & 76.611 & 89.057 & $\mathbf{2 8 5 . 6 4 1}$ \\
\hline 2012 & 22.366 & 72.363 & 18.779 & 84.253 & 99.849 & $\mathbf{2 9 7 . 6 1 0}$ \\
\hline 2013 & 12.623 & 29.957 & 11.520 & 43.328 & 26.279 & $\mathbf{1 2 3 . 7 0 6}$ \\
\hline 2014 & 14.548 & 40.518 & 19.639 & 69.757 & 34.139 & $\mathbf{1 7 8 . 6 0 3}$ \\
\hline 2015 & 12.493 & 40.184 & 15.791 & 40.488 & 26.066 & $\mathbf{1 3 5 . 0 2 3}$ \\
\hline TOTAL & $\mathbf{1 8 6 . 9 5 9}$ & $\mathbf{7 6 1 . 1 6 5}$ & $\mathbf{2 3 9 . 5 7 8}$ & $\mathbf{5 8 4 . 5 1 1}$ & $\mathbf{8 0 1 . 8 8 6}$ & $\mathbf{2 . 5 7 4 . 1 0 1}$ \\
\hline
\end{tabular}

Tabela 3: Quantidade de produtos em toneladas (t) adquiridas. PAA-Regiões - 2003-2015. Fonte: BRASIL. CONAB: Ações da Conab - PAA 2003 a 2015. Org. dos autores.

De acordo com Cruz et al. (s/d), os motivos que levaram a tal oscilação na aquisição dos produtos (visualizar Figura 3) devem-se ao encerramento das operações da CPR-Alimento em 2004, as operações da modalidade Compra Direta 
da Agricultura Familiar (CDAF) e a aquisição de produtos com maior valor agregado, sobretudo, na Compra com Doação Simultânea (CDS). Acrescentam-se também as variáveis climáticas que atingiram algumas regiões e fatores econômicos correlacionados ao mercado.

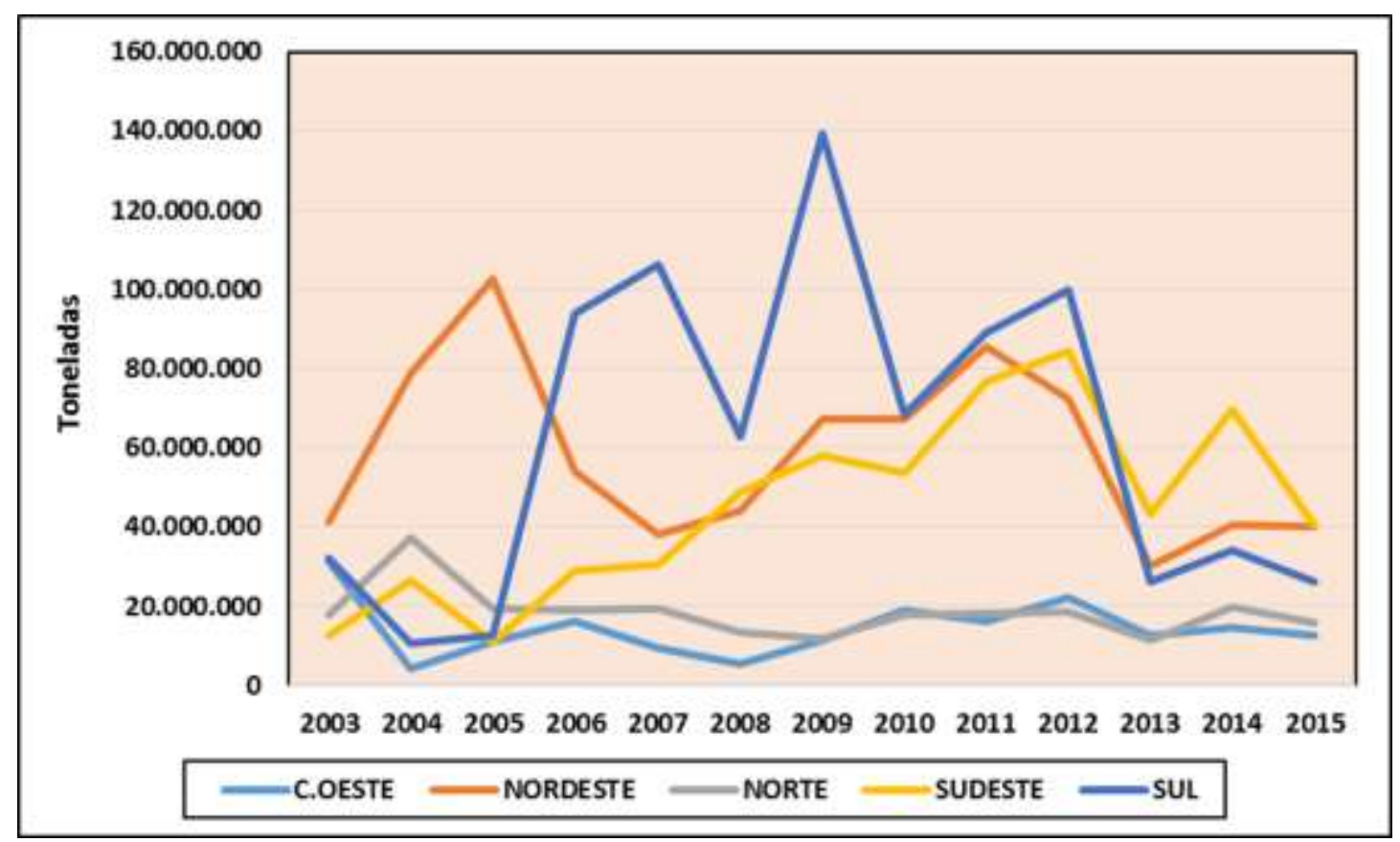

Figura 3: Oscilações na aquisição de produtos. PAA-Regiões - 2003-2015 Fonte: BRASIL. CONAB: Ações da Conab - PAA 2003 a 2015. Org. dos autores.

As oscilações no quantitativo de compras ocorreram com maior incidência nas regiões Sul e Nordeste, desde a implantação do programa. A região Sul passou de 32.307 toneladas em 2003 para 106.232 em 2007 e 139.413 toneladas em 2009, ano em que a região adquiriu a maior quantidade de alimentos. A região Nordeste apresenta uma significativa oscilação entre os anos de 2004/2005, quando atinge 102.582 toneladas adquiridas. Nos anos seguintes, entre 2006 e 2008, apresenta uma diminuição no volume adquirido, voltando a oscilar a partir de 2009.

A região Sudeste ao longo dos anos apresenta oscilações positivas e negativas de crescimento, atingindo sua maior quantidade adquirida em 2012, com 84.253 toneladas. As regiões Centro-Oeste e Norte apresentaram poucas oscilações em comparação com as demais regiões. Todas as regiões apresentam uma substancial diminuição no quantitativo de aquisições entre os anos de 2012/2013. 
Ao longo dos anos de 2003 a 2015, o número de agricultores que tiveram acesso ao PAA cresceu consideravelmente, sendo que em dezembro de 2015 este número chegou a um total de 972.091 agricultores beneficiados (Tabela 4). Pequenas oscilações ocorreram entre os anos de 2007/2008 e 2009/2010 no número de agricultores beneficiados no Brasil.

\begin{tabular}{rrrrrrr}
\hline \multicolumn{7}{c}{ NÚMERO DE AGRICULTORES BENEFICIADOS } \\
\hline ANO & C. OESTE & NORDESTE & NORTE & SUDESTE & \multicolumn{1}{l}{ SUL } & TOTAL \\
\hline 2003 & 5.887 & 19.030 & 6.022 & 3.100 & 7.302 & $\mathbf{4 1 . 3 4 1}$ \\
\hline 2004 & 1.608 & 20.439 & 13.757 & 3.685 & 10.182 & $\mathbf{4 9 . 6 7 1}$ \\
\hline 2005 & 2.656 & 16.315 & 8.544 & 6.091 & 18.369 & $\mathbf{5 1 . 9 7 5}$ \\
\hline 2006 & 4.450 & 22.366 & 8.620 & 13.520 & 37.587 & $\mathbf{8 6 . 5 4 3}$ \\
\hline 2007 & 2.881 & 22.334 & 9.036 & 18.608 & 39.513 & $\mathbf{9 2 . 3 7 2}$ \\
\hline 2008 & 3.154 & 27.135 & 5.130 & 25.161 & 30.043 & $\mathbf{9 0 . 6 2 3}$ \\
\hline 2009 & 3.855 & 29.064 & 5.386 & 22.041 & 37.994 & $\mathbf{9 8 . 3 4 0}$ \\
\hline 2010 & 5.630 & 32.146 & 7.270 & 20.889 & 28.453 & $\mathbf{9 4 . 3 8 8}$ \\
\hline 2011 & 7.480 & 38.595 & 7.175 & 26.935 & 26.415 & $\mathbf{1 0 6 . 6 0 0}$ \\
\hline 2012 & 9.558 & 37.194 & 8.089 & 32.001 & 41.962 & $\mathbf{1 2 8 . 8 0 4}$ \\
\hline 2013 & 4.629 & 13.509 & 4.319 & 11.435 & 7.520 & $\mathbf{4 1 . 4 1 2}$ \\
\hline 2014 & 4.841 & 12.096 & 5.930 & 19.542 & 8.819 & $\mathbf{5 1 . 2 2 8}$ \\
\hline 2015 & 3.821 & 11.845 & 5.139 & 10.284 & 7.705 & $\mathbf{3 8 . 7 9 4}$ \\
\hline TOTAL & $\mathbf{6 0 . 4 5 0}$ & $\mathbf{3 0 2 . 0 6 8}$ & $\mathbf{9 4 . 4 1 7}$ & $\mathbf{2 1 3 . 2 9 2}$ & $\mathbf{3 0 1 . 8 6 4}$ & $\mathbf{9 7 2 . 0 9 1}$
\end{tabular}

Tabela 4: Número de agricultores beneficiados. PAA-Regiões - 2003-2015

Fonte: BRASIL. CONAB: Ações da Conab - PAA 2003 a 2015. Org. dos autores.

O maior número de agricultores beneficiados foi atingido em 2012, seguido de uma expressiva redução no ano de 2013 (67\%), passando de 128.804 em 2012 para 41.412 agricultores em 2013. No ano de 2014, 51.228 agricultores foram beneficiados, crescimento de $23 \%$ em relação à 2013 , seguido de nova redução em 2015 (24\%), quando atinge o menor número de agricultores beneficiados desde a implantação do programa em 2003 (i.e., foram apenas 38.795).

No que concerne às regiões, o aumento no número de agricultores foi expressivo e, em quase todos os anos, com a exceção: dos anos de 2007/2008, na região Norte; 2007/2008, 200/2010/2011 na região Sul; na região Nordeste em 2004/2005 e 2012; na região Sudeste nos anos de 2008/2009/2010; e na região Centro-Oeste no ano de 2004 e entre os anos de 2006/2007. No ano de 2013, todas as regiões apresentaram uma expressiva redução no número de agricultores 
beneficiados. As oscilações no número de agricultores participantes no PAA no decorrer dos anos podem ser visualizadas na figura 4.

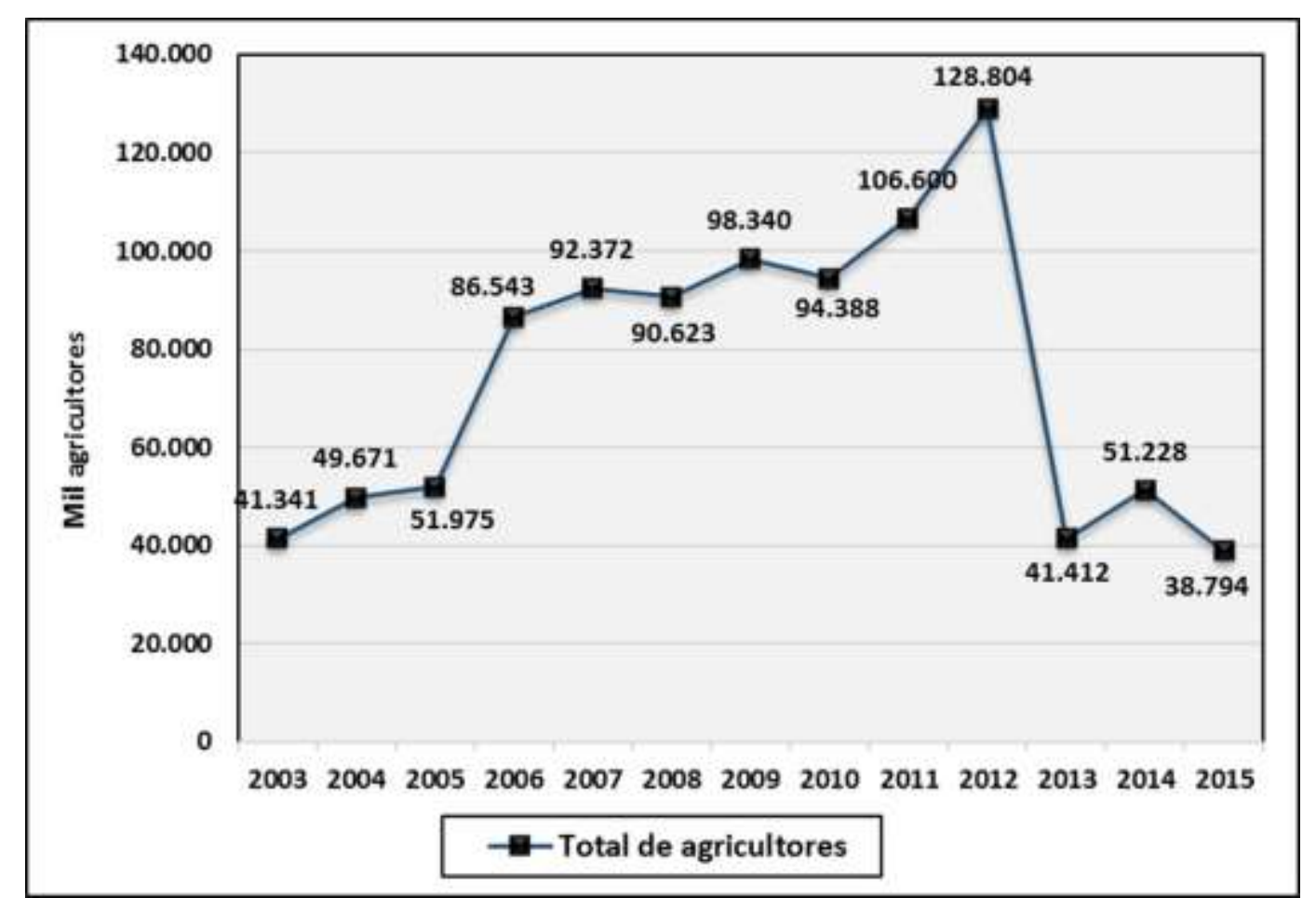

Figura 4: Número de agricultores beneficiados. PAA-Brasil - 2003-2015

Fonte: BRASIL. CONAB: Ações da Conab - PAA 2003 a 2015. Org. dos autores.

Os fatores que podem interferir na variação do número de agricultores beneficiados estão associados à estabilização e/ou oscilação do número de agricultores fornecedores, à elevação e/ou redução da capacidade produtiva, ao aumento do valor médio recebido por agricultor, como também ao gradual aumento dos limites DAP/ano, a implementação do programa em novos municípios e no fortalecimento da confiança dos agricultores junto à Conab, motivada pela garantia na aquisição da produção.

\section{Evolução do número de projetos aprovados}

Dentre as modalidades do PAA executadas pela Conab, a Formação de Estoque pela Agricultura Familiar (CPR-Estoque) e a Compra com Doação Simultânea (CDS), são operacionalizadas por meio de projetos. A tabela 5 e a figura 5 apresentam os dados referentes ao número de projetos executados de 2003 a 2015, amparados por essas duas modalidades, totalizando 16.323 projetos.

Verifica-se, com base na tabela 5, que o número total de projetos no decorrer dos anos, apresenta números variáveis de crescimento, sendo a CDS a modalidade 
que mais apresentou crescimento. $\mathrm{O}$ aumento expressivo na modalidade deve-se ao fato desta contemplar uma grande variedade de produtos (verduras, legumes, frutas, carnes, peixes, pães, doces, produtos regionais e do extrativismo etc.), e por permitir que sejam feitas aquisições de produtos ao longo de todo o ano, incentivando 0 desenvolvimento local/regional e, ao mesmo tempo, contribuindo para o atendimento de pessoas que vivem em situação de insegurança alimentar.

\begin{tabular}{rrrrrrrr}
\hline \multicolumn{7}{c}{ NÚMERO DE PROJETOS APROVADOS POR REGIÃO } \\
\hline ANO & C. OESTE & NORDESTE & NORTE & SUDESTE & SUL & TOTAL \\
\hline 2003 & 0 & 10 & 24 & 2 & 29 & $\mathbf{6 5}$ \\
\hline 2004 & 0 & 50 & 30 & 51 & 113 & $\mathbf{2 4 4}$ \\
\hline 2005 & 15 & 90 & 58 & 125 & 216 & $\mathbf{5 0 4}$ \\
\hline 2006 & 38 & 299 & 109 & 208 & 273 & $\mathbf{9 2 7}$ \\
\hline 2007 & 72 & 530 & 128 & 326 & 440 & $\mathbf{1 . 4 9 6}$ \\
\hline 2008 & 96 & 696 & 140 & 519 & 353 & $\mathbf{1 . 8 0 4}$ \\
\hline 2009 & 56 & 459 & 36 & 441 & 284 & $\mathbf{1 . 2 7 6}$ \\
\hline 2010 & 143 & 871 & 214 & 478 & 361 & $\mathbf{2 . 0 6 7}$ \\
\hline 2011 & 175 & 1.010 & 202 & 626 & 386 & $\mathbf{2 . 3 9 9}$ \\
\hline 2012 & 219 & 1.017 & 198 & 747 & 421 & $\mathbf{2 . 6 0 2}$ \\
\hline 2013 & 122 & 356 & 100 & 237 & 72 & $\mathbf{8 8 7}$ \\
\hline 2014 & 131 & 326 & 141 & 445 & 92 & $\mathbf{1 . 1 3 5}$ \\
\hline 2015 & 115 & 340 & 112 & 248 & 102 & $\mathbf{9 1 7}$ \\
\hline TOTAL & $\mathbf{1 . 1 8 2}$ & $\mathbf{6 . 0 5 4}$ & $\mathbf{1 . 4 9 2}$ & $\mathbf{4 . 4 5 3}$ & $\mathbf{3 . 1 4 2}$ & $\mathbf{1 6 . 3 2 3}$ \\
\hline
\end{tabular}

Tabela 5: Número de projetos aprovados. PAA-Regiões - 2003-2015

Fonte: BRASIL. CONAB: Ações da Conab - PAA 2003 a 2015. Org. dos autores.

Em todas as regiões brasileiras houve redução no número de projetos operacionalizados no ano de 2009, passando de 1.804 projetos em 2008, para 1.276 em 2009, o que representa uma queda de $29 \%$. As regiões que apresentaram os maiores índices de redução foram o Norte (74\%), Centro-Oeste (41\%) e Nordeste (34\%). A mesma redução ocorreu no ano de 2013, porém, com maior expressividade. Em comparação com o ano de 2012, a redução foi de $65 \%$, sendo as regiões Sul e Sudeste as que apresentaram os maiores índices de decréscimo (82\% e 68\%), respectivamente.

Até o ano de 2015, a região Nordeste foi a que teve o maior número de projetos operacionalizados, totalizando 6.054, seguido da região Sudeste com 4.453. A região que apresentou o menor índice de projetos operacionalizados no período 
de 2003 a 2015 foi a região Centro-Oeste, com 1.182 projetos. A região Sul, em especial, apresentou um crescimento anual significativo entre 2003 e 2007, ano em que atinge seu maior número de projetos operacionalizados, quando foram executados 440, número superior ao ano de 2012. Assim como nas demais regiões, a maior redução ocorreu no ano de 2013, chegando a 82\% em comparação com o ano anterior (i.e., 421 vs. 72 projetos). As reduções que ocorrem entre os anos de 2008 e 2009 estão correlacionadas às enchentes que ocorreram no Estado de Santa Catarina, em particular.

As reduções que ocorreram foram de âmbito nacional e estão diretamente associadas à implantação de medidas de atualização da normativa (MOC/NOC) da Conab por recomendação de seu Grupo Gestor e aos fatores já mencionados anteriormente. Assim sendo, muitos dos projetos do ano de 2012 ainda estavam sendo executados em 2013, o que impossibilitou novas contratações, ocasionando, consequentemente, uma redução significativa para o ano de 2013.

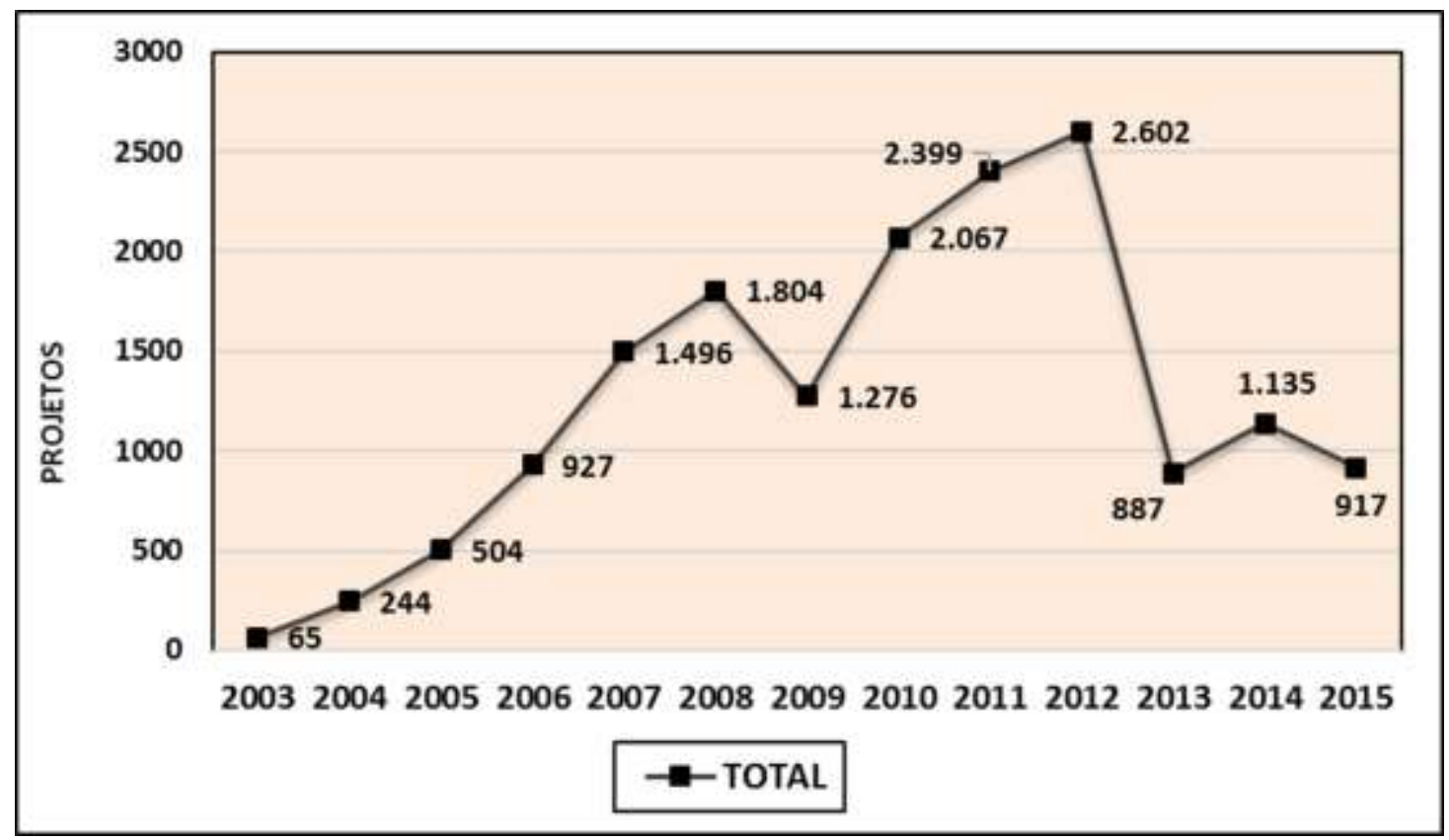

Figura 5: Número de projetos aprovados. PAA-Brasil - 2003-2015

Fonte: BRASIL. CONAB: Ações da Conab - PAA 2003 a 2015. Org. dos autores.

Podemos notar, a partir das variáveis analisadas, que as ações desenvolvidas pela Conab através do PAA ampliaram-se de forma expressiva. O conjunto de políticas públicas implementadas a partir da década 2000, se baseiam na estratégia de integrar políticas de agricultura familiar às políticas de proteção social, colocando a segurança alimentar como centro das ações. A importância das políticas públicas direcionadas para a agricultura familiar se deve, sobretudo, ao valor que esta detém 
na garantia da segurança alimentar e nutricional, sendo primordial a elaboração destas com o intento de maximizar o potencial de produção e possibilitar a permanência e a continuidade desta parcela social no campo.

Por seu turno, a importância da agricultura familiar no cenário nacional é incontestável, principalmente por abastecer grande parte do mercado consumidor, dinamizando não somente a estrutura econômica, como também a social. Os dados do Censo Agropecuário de 2006, publicados pelo IBGE em 2009, revelam que, dos 5,1 milhões de estabelecimentos rurais existentes no país, 4,3 milhões são considerados da agricultura familiar, empregando, aproximadamente, 75\% da mãode-obra do setor. Ainda de acordo com o Censo Agropecuário de 2006, a agricultura familiar responde por $70 \%$ do feijão, $34 \%$ do arroz, $46 \%$ do milho, $21 \%$ do trigo, $87 \%$ da mandioca, $38 \%$ do café, $58 \%$ do leite, $30 \%$ dos bovinos, $59 \%$ do plantel de suínos e, ainda, $50 \%$ das aves. E, apesar de ocupar apenas $1 / 4$ da área $-24,3 \%$, responde por $38 \%$ do valor da produção agropecuária, o que equivale a $R \$ 54$ bilhões (IBGE, 2009).

Neste contexto, o PAA merece especial atenção entre as políticas públicas, principalmente, por promover o desenvolvimento da agricultura familiar, levando em consideração as particularidades locais. Neste caso, para que possam ocorrer as alterações necessárias e desejáveis no quadro social, as políticas públicas devem ser pensadas em conjunto com a sociedade e articuladas nas mais diversas esferas de poder, para que possam, de fato, caminhar rumo à construção de uma sociedade mais justa.

\section{Considerações Finais}

Inserido no âmbito do conjunto das políticas pertencentes ao Programa Fome Zero - que articula políticas emergenciais com políticas estruturais - as ações do PAA, embora ainda sejam tímidas se comparadas ao número total de estabelecimentos da agricultura familiar e a importância da política pública para o conjunto desta, tem gerado efeitos positivos para essa categoria de produtores rurais, promovendo de um lado, o acesso à alimentação, e de outro, incentivando-a por meio da compra direta de alimentos. Ao cumprir a função de suprir as necessidades alimentares e nutricionais e, ao mesmo tempo, estimular a agricultura familiar, o programa promove o fortalecimento dos circuitos locais e regionais de comercialização, inserindo, nos mercados institucionais, agricultores situados à margem do processo produtivo. Nesta perspectiva, o programa pode ser 
compreendido como um instrumento capaz de articular o poder de compra do Estado, conectando a oferta local da agricultura familiar com os segmentos vulneráveis da população.

As variáveis analisadas evidenciam a importância da política para o contexto da agricultura familiar. Ao longo de 12 anos de execução, o Governo Federal já investiu mais de três bilhões de reais no programa, adquiriu produtos de cerca de 1,3 milhão de famílias de agricultores familiares, totalizando aproximadamente 2,5 milhões de toneladas de alimentos. De 2003 a 2015, foram 16.323 projetos aprovados, viabilizando mais de 970 mil acessos de agricultores ao programa. Mais de 75.000 unidades recebedoras foram beneficiadas em 2.729 municípios brasileiros.

Todavia, é possível notar que a partir de 2013, os recursos orçamentários destinados ao programa foram drasticamente reduzidos. Tem-se, de um lado, sucessivas adequações nos manuais e normativos da Conab, uso indevido de recursos do programa em nível de Brasil, problemas climáticos associados a enchentes e secas, dentre outros fatores que contribuíram para a redução das variáveis analisadas. Por outro lado, o cenário de reduções reflete a crise política e econômica que se acirrou após a reeleição da presidenta Dilma Roussef (2014) e, sobretudo, após o golpe parlamentar que a depôs, quando ocorreram diversos cortes nos investimentos públicos, em diversas áreas e programas sociais, a exemplo do PAA.

Embora não esteja isento de críticas e desafios, é inquestionável o reconhecimento de que o programa vem alcançando resultados positivos ao proporcionar para o agricultor e para o meio rural, segurança de mercado, garantia de preços compensatórios e autonomia em relação aos intermediários, criando condições para a superação da insegurança alimentar e nutricional de milhões de famílias por meio da inclusão social no meio rural.

Por fim, ainda que seja recente sua trajetória, o programa tem conseguido legitimidade social, consolidando-se em um instrumento capaz de estimular o desenvolvimento local, garantindo o direito de acesso à alimentação adequada. 


\section{REFERÊNCIAS}

BRASIL - Companhia Nacional de Abastecimento (CONAB). Produtos e Serviços: Ações da Conab - PAA 2003 a 2015. Disponível em: < http://www.conab.gov.br/conteudos.php?a=1402\&t=2>. Acessado em 15 de jan. de 2015.

BRASIL - Companhia Nacional de Abastecimento. Programa de Aquisição de Alimentos: Legislação Básica, 2015. Disponível em: <http://www.conab.gov.br/OlalaCMS/uploads/arquivos/15_12_07_17_25_57_livreto_paa_c orreta.pdf $>$. Acessado em: 22 de abr. de 2017.

BRASIL. Controladoria Geral da União. Relatório de Avaliação da Execução de Programa de governo $n^{\circ}$ 52. Aquisição de Alimentos provenientes da agricultura familiar. Brasília, 2016.

BRASIL - Ministério do Desenvolvimento Social e Combate à Fome (MDS). Segurança Alimentar: Modalidades, $2017 . \quad$ Disponível em: <http://www.mda.gov.br/sitemda/secretaria/saf-paa/modalidades-do-paa>. Acessado em: 20 de abr. de 2017.

CRUZ, Kelma C. Melo dos Santos; et al. 0 acesso da agricultura familiar brasileira às políticas públicas: a evolução do Programa de Aquisição de Alimentos. s/d.

DELGADO, Guilherme Costa. Relatório de Avaliação do PAA - Ill: Síntese, 2013, (mimeo).

CAMPOS, Arnoldo de; BIANCHINI, Valter. A Agricultura Familiar passa a ser uma prioridade de Estado. In: Brasil. Ministério do Desenvolvimento Social e Combate à Fome. PAA: 10 anos de aquisição de alimentos. -- Brasília, DF: MDS; Secretaria Nacional de Segurança Alimentar e Nutricional; Secretaria de Avaliação e Gestão da Informação, p. 10-17, 2014.

HESPANHOL, Rosangela A. M. Programa de Aquisição de Alimentos: limites e potencialidades de políticas de segurança alimentar para a agricultura familiar. Revista Sociedade e natureza, v. 25, p. 469-483, 2013.

HESPANHOL, Rosangela A. M. A adoção da perspectiva territorial nas políticas de desenvolvimento rural no Brasil. Revista Campo - Território, v. 05, p. 123-147, 2010.

IBGE - INSTITUTO BRASILEIRO DE GEOGRAFIA E ESTATÍSTICA. Censo Agropecuário 2006. Agricultura Familiar. Primeiros resultados. Brasil. Grandes Regiões e Unidades da Federação. 262p. 2009.

MIELITZ, Carlos. Dez anos de PAA e a constituição de uma estratégia Nacional de Segurança Alimentar. In: Brasil. Ministério do Desenvolvimento Social e Combate à Fome. PAA: 10 anos de aquisição de alimentos. -- Brasília, DF: MDS; Secretaria Nacional de Segurança Alimentar e Nutricional; Secretaria de Avaliação e Gestão da Informação, p. 5873, 2014.

OLIVEIRA, Adriano Rodrigues de. 0 associativismo na região do Pontal do Paranapanema-SP: Limites e possibilidades para o desenvolvimento rural. 2010. $209 \mathrm{f}$. Tese (Doutorado em Geografia) - Universidade Estadual Paulista "Julio de Mesquita Filho", Presidente Prudente, 2010.

SCHMITT, Claudia Job. Aquisição de alimentos da agricultura familiar: Integração entre política agrícola e segurança alimentar e nutricional. Revista de Política Agrícola, n. 2, p. 78-88, 2005. 
SCHNEIDER, Sergio. Teoria Social, Agricultura Familiar e pluriatividade. Revista Brasileira de Ciências Sociais, v. 18, p. 99-121, 2003.

VALNIER, Adilson; RICCI, Fabio. Programa de Aquisição de Alimentos (PAA): uma análise comparativa nos estados de Rondônia e Acre. Revista Campo - Território, v. 08, p. 198228, 2013.

\section{NOTAS DE AUTOR}

\section{CONTRIBUIÇÃO DE AUTORIA}

Carla Hentz - Concepção. Coleta de dados, Análise de dados, Elaboração do manuscrito, revisão e aprovação da versão final do trabalho.

Rosangela Aparecida de Medeiros Hespanhol - Orientação, colaboração e correção do manuscrito. Participação ativa da discussão dos resultados; Revisão e aprovação da versão final do trabalho.

\section{FINANCIAMENTO}

Os autores agradecem à Fundação de Amparo à Pesquisa do Estado de São Paulo (FAPESP) pelo apoio financeiro inscrito no processo número 2014/02873-4.

\section{CONSENTIMENTO DE USO DE IMAGEM}

Não se aplica

\section{APROVAÇÃO DE COMITÊ DE ÉTICA EM PESQUISA}

Não se aplica.

\section{CONFLITO DE INTERESSES}

Não se aplica.

\section{LICENÇA DE USO}

Este artigo está licenciado sob a Licença Creative Commons CC-BY. Com essa licença você pode compartilhar, adaptar, criar para qualquer fim, desde que atribua a autoria da obra.

\section{HISTÓRICO}

Recebido em: 02-10-2018

Aprovado em: 19-11-2018 